\title{
CORROSION ON ELECTRIC FUEL PUMP HOUSING AT DURABILITY TEST IN TEST BENCH
}

Celso Eduardo Fávero, Leandro Barcellos de Souza, Fabiane Pacheco, Mário Celso Duarte Pereira.

\author{
Robert Bosch Limitada - Brazil \\ E-mails: celso.favero@br.bosch.com, leandro.souza4@br.bosch.com, \\ fabiane.pacheco@br.bosch.com, mario.pereira@br.bosch.com
}

\begin{abstract}
For lifetime verification in automotive components it is necessary to simulate their operation in test benches that reproduce the conditions of vehicular application, according to the boundary conditions defined in the project.

In durability tests of electric fuel pumps for Otto cycle engines, test benches are often used comprised of fuel tanks made of stainless steel provided with a fuel temperature control system. They also have a hydraulic system that allows simulating the fuel circulation loop of the vehicle consisting of fuel filter and fuel pressure regulator. Moreover, they are also equipped with flow meters and fuel pressure for monitoring the test.
\end{abstract}

It has been observed in test bench durabilities that fuel pumps of Flex Fuel type are likely to present high levels of corrosion on their outer housing, even higher than expected after this kind of test. However this behavior has not been found in automotive vehicles under real conditions of use and after a long period of running, suggesting that the problem lies in the operational conditions of the test bench itself.

This paper aims to study the cause of this phenomenon, associated with the ground difference between the bench and the tank of the vehicle, describe it from a theoretical perspective and propose modifications to the settings that best simulate the test vehicle conditions, leading to more reliable results at the end of the test.

\section{INTRODUCTION}

In a fuel injection system the task of the electric fuel pump is to supply the vehicle engine with sufficient fuel under all operating conditions. Almost all the current applications have its fuel pump installed inside the vehicle fuel tank in a supply module as shown in the figure 1.

Most of these in-tank electric fuel pumps have a very similar structure: A permanent-magnet electric motor is assembled internally to a tubular metal housing and has its shaft directly connected to a hydraulic pumping unit, also mounted inside the same housing. The fuel suction occurs through a suction port on the inlet cover of the pumping unit. The pressurized fuel is than supplied to the vehicle system through a hydraulic tube connection located at the end support cover of the pump, which is used to close the pump assembly. This cover also 
contains the electrical terminals that provide the power supply to the electric motor through the brushes/commutator system, leading the electricity for the motor armature.

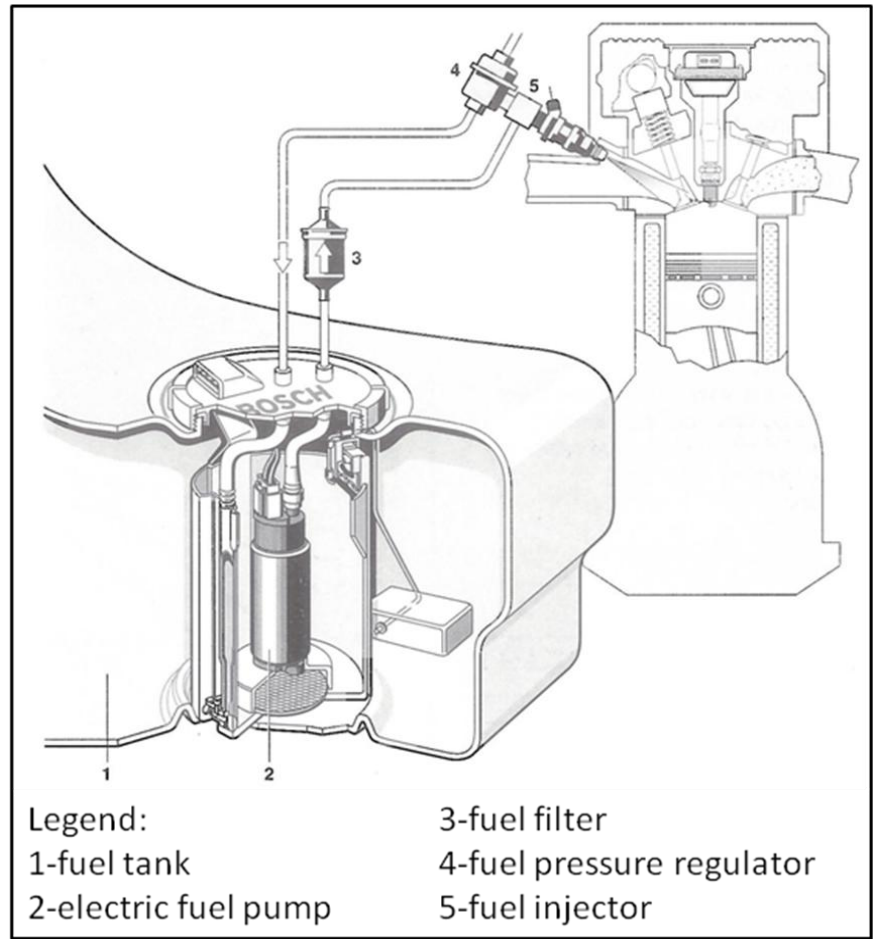

Figure 1: fuel pump supply module

The figure 2 shows a typical section view of an electric fuel pump and its main components.

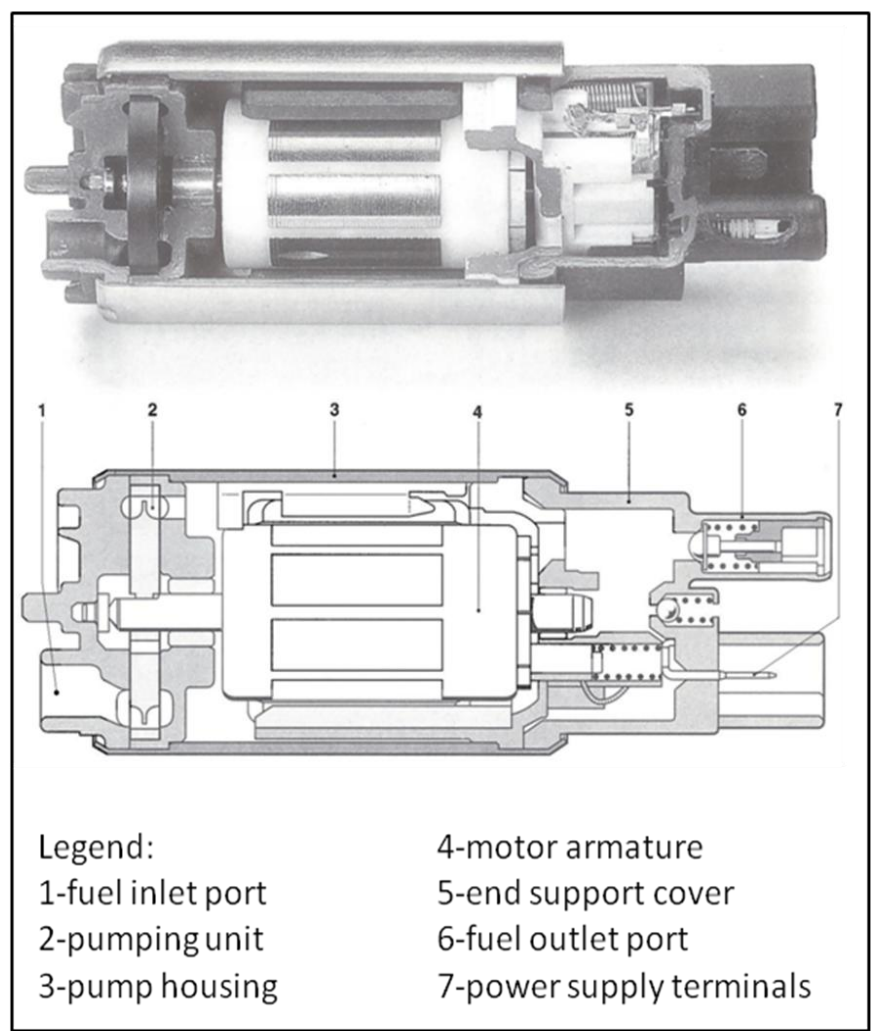

Figure 2. Internal components of an electric fuel pump 
To meet the basic goal of all automotive components (higher efficiency with the smaller size / weight as possible), in such kind of electric pumps construction, the fuel flow is used as a coolant, flowing around its internal components, removing the heat generated by the electric motor, thus enabling its dimensions to be relatively reduced.

This constructive principle therefore requires that all pump's components are dimensioned to withstand to the chemical aggressiveness of the operating fuels, whether gasoline or ethanol, particularly in Flex Fuel applications.

In addition, there is the action over some of the pump parts of an electrochemical corrosion potential, which is generated due to the energized components connected to the power circuit of the electric motor and which are exposed directly to the fuel.

This electrochemical corrosion potential depends directly on the voltage difference applied between these metal components. However, this kind of corrosion will actually only occur if the working fuel can provide sufficient conductivity to establish the corrosion current through this medium.

As explained by Yuen et.al [1] and Fox et.al [2], the fuel conductivity is linked directly to their composition and in blends of gasoline and ethanol, as higher the content of ethanol in the mixture the greater will be the value of the final conductivity.

Although gasoline is considered a non-conductive fluid itself, its combination with ethanol makes the final mixture more conductive. This is given by hygroscopic characteristic of ethanol that can absorb water more easily than gasoline. This water content becomes more susceptible to ethanol solubilization of corrosive salts such as sodium chloride and potassium chloride. In addition, organic acids such as acetic acid and formic acid are sub-products of the ethanol production process and if not properly controlled and neutralized they are also soluble in ethanol. This combination of acids and salts raises the fuel conductivity, which will be greater the higher the water content in the composition.

It must also be considered that most countries that adopt the Flex Fuel program based on bioethanol often add anhydrous ethanol ( $<1 \%$ water by volume) in an amount up to $85 \%$ ethanol to the gasoline (E-85 fuel). The exception at the moment is Brazil, which adopted in its regular gasoline the addition of $22 \pm 4 \%$ anhydrous ethanol (E22 fuel), but also provides hydrous ethanol (E100) as an alternative fuel in that market. This hydrous ethanol should contain up to $5 \%$ water by volume in the composition according to ANP Regulation [3], although values up to $7 \%$ are regularly found in the market due to the hygroscopic property of ethanol. And as this E100 fuel is used in the Flex Fuel program in Brazil, it is directly responsible for the higher conductivity on the final fuel composition.

The table 1 shows the various values of fuel conductivity between gasoline and their mixtures with ethanol, measured at $20^{\circ} \mathrm{C}$, reaching a maximum by the use of $100 \%$ hydrous ethanol in Brazilians applications. Usually, an increase in the concentration of ethanol and water as well as the temperature increases the conductivity of the fuel.

It is also known that in the process of fuel distribution, from the distributors to the gas stations, contamination usually occurs whether unintentional (reservoir tank trucks not properly cleaned, underground tanks of gas stations leaking, etc. ..) as well as deliberate 
tampering (for example, by adding ethanol in E22 gasoline E22 or addition of water in ethanol E100).

Table 1 - Regular Fuels and conductivities

\begin{tabular}{|l|l|}
\hline \multicolumn{1}{|c|}{ Regular Fuels [3], [4],[ 5] } & Conductivity (pS/m) \\
\hline E0: Pure Gasoline without ethanol & $1 \sim 1000$ (reference) \\
\hline E22: Gasoline with addition of 22 $\pm 4 \%$ of anhydrous ethanol. & $20 \times 10^{6}$ (reference) \\
\hline $\begin{array}{c}\text { E85: } 75 \text { to 85 volume \% of fuel ethanol and 25 to } 15 \\
\text { additional volume \% of gasoline }\end{array}$ & $180 \times 10^{6}$ (reference) \\
\hline E100: 100\% Hydrous Ethanol Fuel & $350 \times 10^{6}$ max. \\
\hline
\end{tabular}

Aiming to equip their vehicles with more robust components, which are able to meet their projected operational life even in the presence of a certain type of contamination, the automakers have adopted standards for test fuels whose composition aims to reproduce the levels of contamination found in most common market research, whether their own research or else government agency such as the ANP.

An example is also shown in Table 2 which brings references of conductivity of some aggressive Ethanol fuels as to be used in durability testing of fuel pumps in test bench according to German automakers specification AK-LH 15 [6]

Table 2 - Test Fuels and conductivities

\begin{tabular}{|c|c|}
\hline Aggressive Test Fuels [6] & Conductivity $(\mathbf{p S} / \mathbf{m})$ \\
\hline RSG-E85 & $250 \times 10^{6} \max$. \\
\hline E100-2000 & $1400 \sim 1700 \times 10^{6}$ \\
\hline
\end{tabular}

\section{Corrosion of pump housing in test bench}

The Brazilian program of Flex Fuel completes 10 years of existence in 2013. During these years, the experiences in the field with respect to aggressive fuels were incorporated in laboratory tests aimed to simulate the effects of these fuels on the durability of the products. It has been then observed a tendency to adopt no more the E100 fuel according to the ANP standard for durability tests of electric fuel pumps, but an E100 aggressive whose composition is specified by each automaker as its own experience. In addition, some durability cycles were introduced where the fuel temperature has been increased to around 50 to $60{ }^{\circ} \mathrm{C}$ in order to simulate extreme operating conditions.

After the introduction of these changes it was observed for the first time at the end of the fuel cycle durability in aggressive E100, a state of corrosion on the outer surface of the electric fuel pump housing which drew the attention due to the following specific facts:

a. Corrosion is prevalent throughout the outer surface of the housing, but hardly any occurs in the inside, although it is also immersed in the same test fuel. 
b. Electric fuel pumps non energized and submitted to immersion tests in aggressive fuel for extended periods (90 days) and high temperature $\left(70^{\circ} \mathrm{C}\right)$ did not show such high levels of corrosion.

c. Field surveys with electric fuel pumps that had long periods of use ( $>5$ years and $>70,000$ $\mathrm{km}$ ) revealed no corrosion problems in this component.

Figure 3 shows the difference between the states of corrosion found in fuel pumps in the field and that found after durability in test bench.

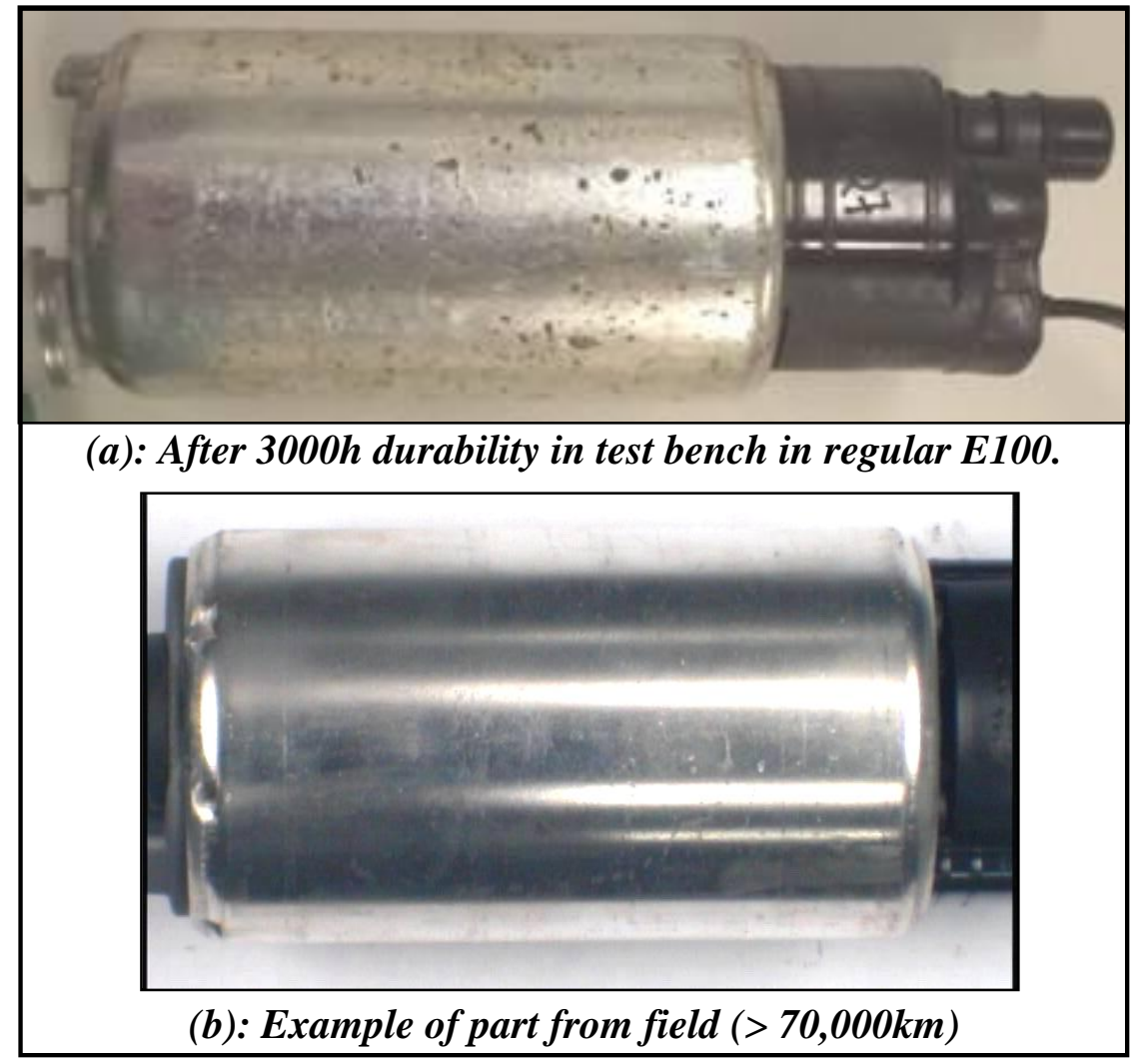

Figure 3. Aspect of outer surface of the electric fuel pump

Discarded the possibility of chemical corrosion as the root cause by combining the observations of the internal state of the housings in item a. with the final result of item $b$. above mentioned, the study focused on the operating conditions of the test bench for durability of electric fuel pumps, whose schema constructive can be seen in figure 4 .

This test bench is usually composed of a stainless steel tank, equipped with fuel temperature control system through a heat exchanger. Inside this tank samples of fuel pumps to be tested are assembled and connected to a hydraulic circuit of fuel circulation which aims to simulate the equivalent circuit of the car where they are applied.

Due to the use of fuels during the test, these benches are usually installed in special rooms constructed as explosion-proof where atmospheric air is continuously replaced by ventilation systems in order to avoid a dangerous concentration of explosive gases. 


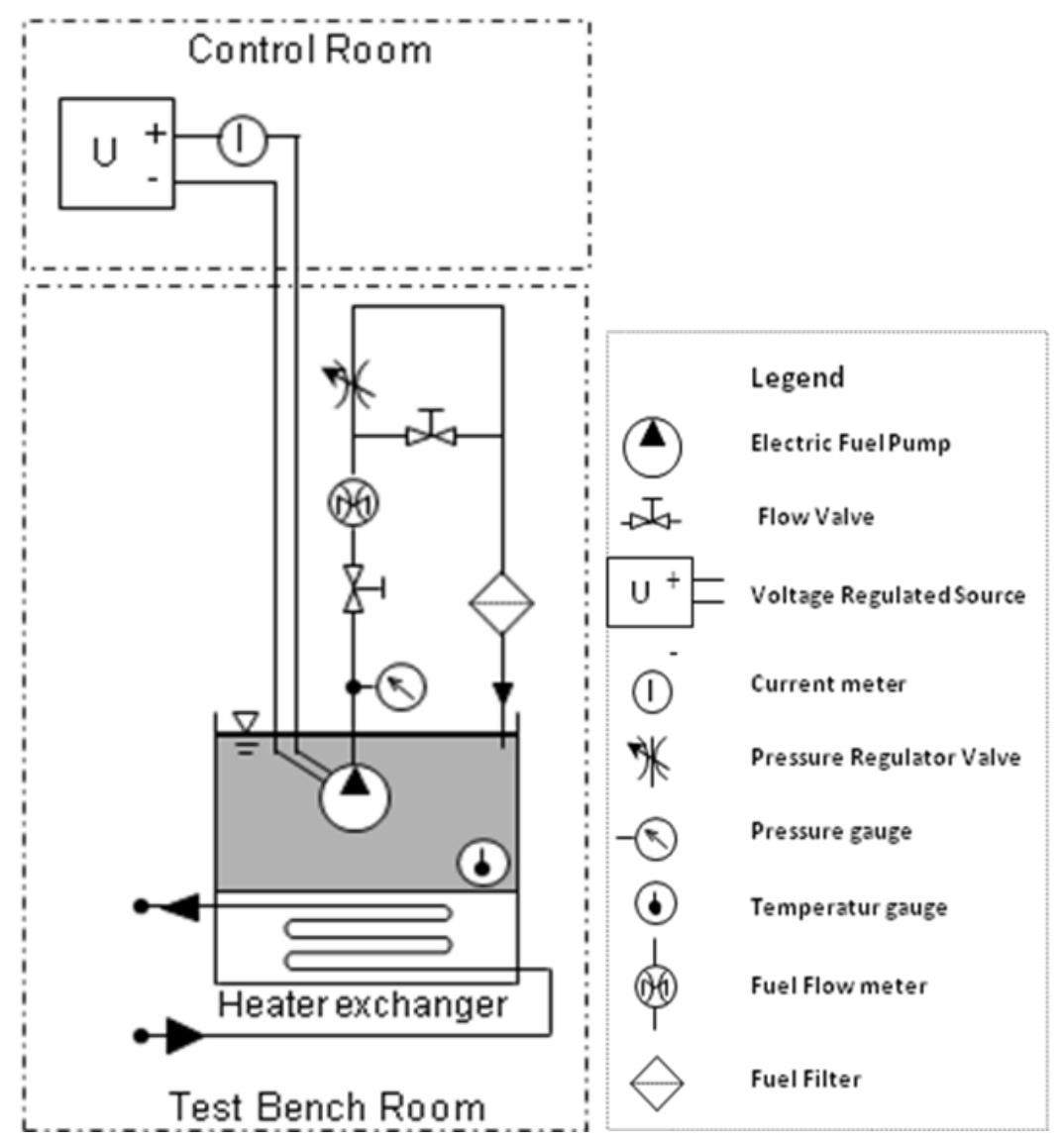

Figure 4. Constructive schema of a test bench for durability test of Electric Fuel Pump

Also for safety and to reduce the costs of the facilities, the power sources that provide and control the supply voltage to the fuel pump under test are installed in separate rooms next to where the test benches are located. Thus, because they are not operating in an environment subject to an explosive atmosphere, these devices may be of the conventional type, not requiring any special explosion protection, minimizing investment costs.

This separation between the control and the test benches rooms requires long power supply cables and due to its natural electrical resistance, cause a significant voltage drop to the power terminals of the pump under test. This voltage drop must then be compensated by the sources in order to maintain the desired voltage level applied to the sample under test.

This is done automatically by its own power sources, because the equipment usually adopted has an automatic control via voltage sensor, consisting of an extra pair of wires that monitors the voltage applied directly at the power terminals of the fuel pump being tested. (Power source with voltage compensation)

\section{Theoretic study of the problem}

For an explanation of the corrosion phenomenon that occurs in fuel pump housings during the durability in test benches, the Figure 5 shows a simple diagram of the electric set-up of the electric fuel pump when it is mounted on the test bench for a durability test. 


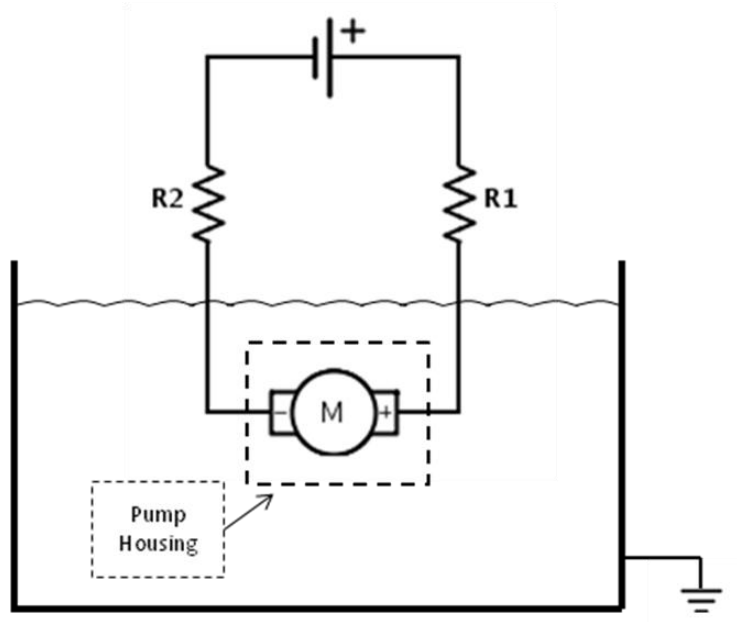

Figure 5. Electric diagram of the test bench set-up for durability test.

During operation, the electric fuel pump is completely soaked in fuel. Resistors $R_{1}$ and $R_{2}$ correspond to the electric resistances of the cables that connect the power supply at the control room to the sample under test in the test bench. The metallic tank is grounded.

Considering that the ground terminal from the metallic tank is on the same bus of the ground terminal from the power supply (therefore they have the same potential), figure 6 shows a simplified equivalent electric circuit of the system involved on the electric fuel pump operation, as well as possible ways of electrolytic corrosion that may exist due to the conductivity of the test fuel.

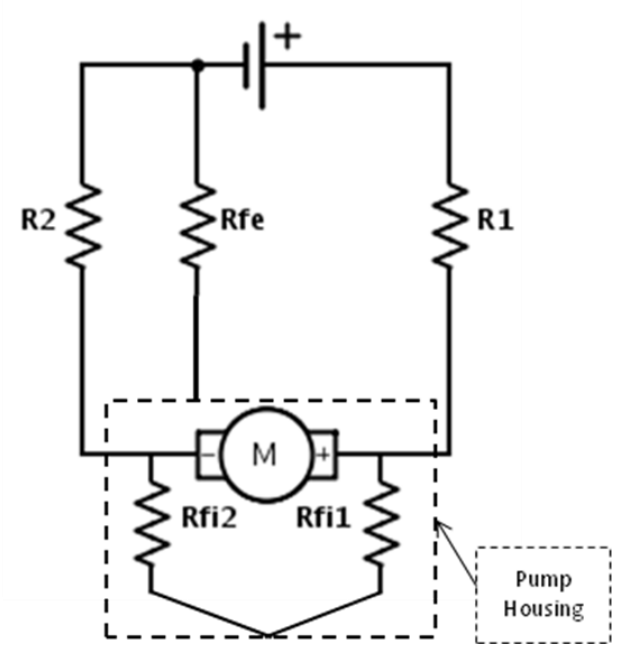

Figure 6. Equivalent simplified electric circuit of the electric fuel pump assembled in the test bench.

Where:

- $\mathrm{R}_{1}$ : electric resistance from the power supply's positive cable;

- $\mathrm{R}_{2}$ : electric resistance from the power supply's negative cable;

- $\mathrm{R}_{\mathrm{Fi} 1}$ : fuel internal electric resistance between positive brush from the electric fuel pump and the pump housing; 
- $\mathrm{R}_{\mathrm{Fi} 2}$ : fuel internal electric resistance between negative brush from the electric fuel pump and the pump housing;

- $\mathrm{R}_{\mathrm{Fe}}$ : fuel external electric resistance between the pump housing and the ground terminal of the test bench tank.

Additional losses are not being considered.

When the electric fuel pump is operating, the energy supplied is used by the electric motor to produce torque and consequently drive the hydraulic package responsible for the pumping function. However, due to the electric potential of the energized components and the fuel's conductivity, another electric path appears in the fuel allowing extra currents to flow. These currents are known as leakage currents.

For the corrosion mechanism analysis it can be considered that the leakage currents are located in two specific regions: i) inside the pump housing of the electric fuel pump, corresponding to currents through resistors $\mathrm{R}_{\mathrm{Fi} 1}$ and $\mathrm{R}_{\mathrm{Fi} 2}$ and ii) outside the pump housing interacting with the environment through resistor $\mathrm{R}_{\mathrm{Fe}}$.

Figure 7 shows the same circuit previously defined reorganized for a better visualization and easier analysis. The resistor $\mathrm{R}_{\mathrm{m}}$ was included to represent all resistances related to the electric fuel pump (armature, brushes, etc):

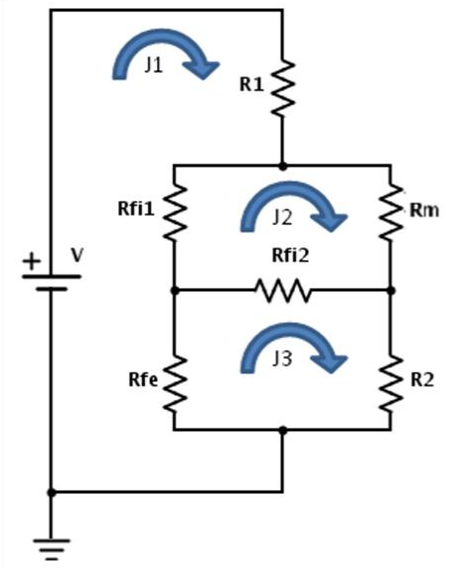

Figure 7. Equivalent electric circuit of an electric fuel pump assembled in the test bench reorganized.

According to the Mesh Current Method, based on Kirchhoff's circuit laws, it is possible to identify three different loops that characterize the meshes. The currents $J_{1}, J_{2}$ and $J_{3}$ that run through these loops are known as mesh currents. It is possible to calculate the voltage drop over each component by following the current direction adopted in the loop. The equations for each mesh can be found below:

I: $\quad R_{1} J_{1}+R_{F i 1}\left(J_{1}-J_{2}\right)+R_{F e}\left(J_{1}-J_{3}\right)=V$

II: $\quad R_{m} J_{2}+R_{F i 2}\left(J_{2}-J_{3}\right)+R_{F i 1}\left(J_{2}-J_{1}\right)=0$

III: $\quad R_{2} J_{3}+R_{F e}\left(J_{3}-J_{1}\right)+R_{F i 2}\left(J_{3}-J_{2}\right)=0$ 
Evaluating each term from the equations and comparing them with real measurements, the following considerations can be made:

$R_{F i 1}\left(J_{1}-J_{2}\right)=V_{R_{F i 1}}$

$R_{F e}\left(J_{1}-J_{3}\right)=V_{R_{F e}}=V_{H G}=>$ Housing - Ground

$R_{F i 2}\left(J_{3}-J_{2}\right)=V_{R_{F i 2}}=V_{H N}=>$ Housing - Negative terminal

Hence, equations can be rewritten as:

I: $\quad V_{R 1}+V_{R_{F i 1}}+V_{H G}=V$

II: $\quad V_{R_{m}}-V_{H N}-V_{R_{F i 1}}=0$

III: $V_{R 2}-V_{H G}+V_{H N}=0$

In order to verify whether the equations above are representing the system properly, the table 3 shows some measurements taken from three different electric fuel pump models, with different current consumptions, mounted to the test bench.

Remark: the results shown on table 3 are valid only for reference and comparison between the theoretical calculations and real measurements. The values may vary according to test fuel characteristics and pump assembly position in the test bench.

Table 3. Comparison between measured and calculated voltage drops.

\begin{tabular}{|c|c|c|c|c|c|c|}
\hline \multirow[b]{2}{*}{ Variables } & \multicolumn{2}{|c|}{$\begin{array}{l}\text { Model } 1 \\
\text { [V] }\end{array}$} & \multicolumn{2}{|c|}{$\begin{array}{c}\text { Model } 2 \\
\text { [V] }\end{array}$} & \multicolumn{2}{|c|}{$\begin{array}{l}\text { Model } 3 \\
{[\mathrm{~V}]}\end{array}$} \\
\hline & Measured & Calculated & Measured & Calculated & Measured & Calculated \\
\hline V & 13,90 & - & 13,90 & - & 13,90 & - \\
\hline $\mathrm{V}_{\mathrm{R} 2}$ & 0,23 & - & 0,30 & - & 0,34 & - \\
\hline $\mathrm{V}_{\mathrm{m}}$ & 12,54 & - & 11,93 & - & 11,62 & - \\
\hline $\mathrm{V}_{\mathrm{RFi}_{2}}=\mathrm{V}_{\mathrm{HN}}$ & 0,70 & - & 0,48 & - & 0,50 & - \\
\hline $\mathrm{V}_{\mathrm{R} 1}(\mathrm{Eq} . \mathrm{I})$ & 1,13 & 1,20 & 1,68 & 1,74 & 1,93 & 2,00 \\
\hline $\mathrm{V}_{\mathrm{RFi1}}(\mathrm{Eq} . \mathrm{II})$ & 11,75 & 11,59 & 11,39 & 11,16 & 11,06 & 10,78 \\
\hline $\mathrm{V}_{\mathrm{RFe}}=\mathrm{V}_{\mathrm{HG}}(\mathrm{Eq} . \mathrm{III})$ & 0,95 & 0,93 & 0,77 & 0,78 & 0,84 & 0,84 \\
\hline
\end{tabular}

The measurements are very close to the calculated values, showing that the equivalent circuit and the equations described previously are reliable to evaluate the system. The difference between both values can be attributed to measurement errors.

The term $\mathrm{V}_{\mathrm{HG}}$ corresponds to the voltage drop on the resistor $\mathrm{R}_{\mathrm{Fe}}$, which means it is related to the fuel conductivity outside the metallic pump housing. The occurrence of this term implies in a leakage current between the metallic pump housing and the ground terminal of the test bench (connected to the metallic tank). This leakage current 
characterizes an electrolysis process, which causes the small corrosion spots on the pump housing, shown on figure 3 a.

By rewriting equation III, the following relation is found:

$V_{H G}=V_{R 2}+V_{H N}$

The term $\mathrm{V}_{\mathrm{HN}}$ corresponds to a voltage drop on the resistor $\mathrm{R}_{\mathrm{Fi} 2}$, whose value is also related directly to the fuel conductivity. Therefore it is determined according to the specification of each durability test, hence cannot be changed. For that reason, in order to decrease $V_{H G}$ value (and consequently reduce the corrosion) it is necessary to reduce $\mathrm{V}_{\mathrm{R} 2}$ (by decreasing the resistance of the negative cable $\mathrm{R}_{2}$ ).

As already described previously, the existence of $R_{2}$ is completely related to constructive aspects of the test bench, therefore there are limitations regarding implementation and costs that impacts on the feasibility to reduce its value. An alternative to eliminate $V_{\mathrm{HN}}$ is to ground the metallic pump housing as shown on figure 8.

The pump housing grounding corresponds to a short-circuit that removes the resistance $\mathrm{R}_{\mathrm{Fe}}$ from the electric circuit, causing the metallic pump housing to achieve the same potential from the metallic tank, eliminating the electrolysis that causes the corrosion.

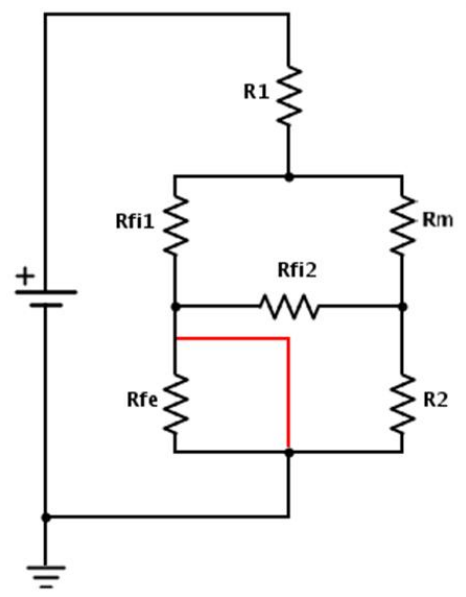

Figure 8. Equivalent electric circuit with metallic pump housing grounded.

Although the metallic pump housing is not grounded in the vehicle, usually the tanks from flex fuel applications are made of plastic materials. This means that one of the terminals from the resistance $R_{\mathrm{Fe}}$ is not connected to the ground through the fuel, leading to an open loop, as shown on Figure 9 and consequent no current draw.

For vehicles with metallic tanks, the value from the resistor $\mathrm{R}_{2}$ is smaller than the condition in the test bench due to the short distance between the electric fuel pump and the battery's negative terminal or grounding at vehicle's frame. In comparison with the test bench, in this situation, the voltage applied to the negative terminal of the fuel pump will not be zero but will assume a value correspondent to the voltage drop in the negative supply cable $\left(V_{R 2}\right)$ of the test bench. In order to compensate this situation and better reproduce the vehicle condition, it is recommended to connect the negative pump 
terminal to the test bench ground terminal. Then the voltage applied to the positive pump terminal will be reduced by a value equivalent to $V_{R 2}$ by the compensation system of the power supply, leading the pump housing to assume a reduced voltage potential in comparison to the test bench tank. In consequence the corrosion potential will be also reduced.

Another solution already discussed for some applications is the connection of the pump housing on the negative brush terminal as shown in figure 10. With this configuration, the resistor $\mathrm{R}_{\mathrm{Fi} 2}$ will be removed from the circuit. However, the resistor $\mathrm{R}_{\mathrm{Fe}}$ will still be connected to the electric circuit allowing a leakage current to flow through it. This leakage current may be smaller than the condition without this grounding, but it will exist, still leading to corrosion through electrolysis.

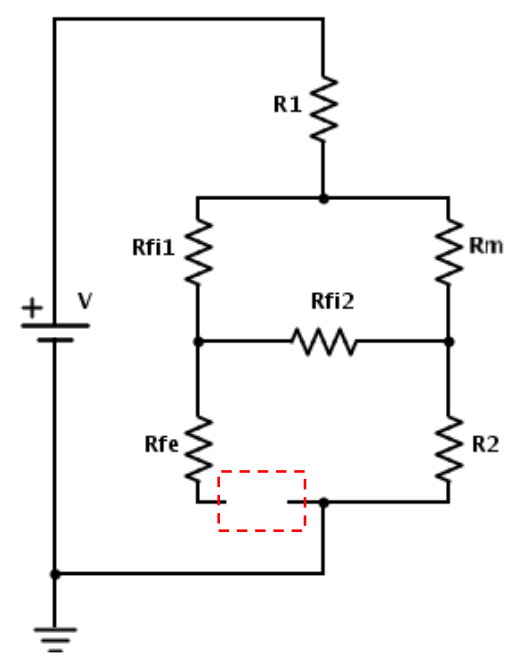

Figure 9. Electric circuit from a electric fuel pump assembled in a plastic tank.

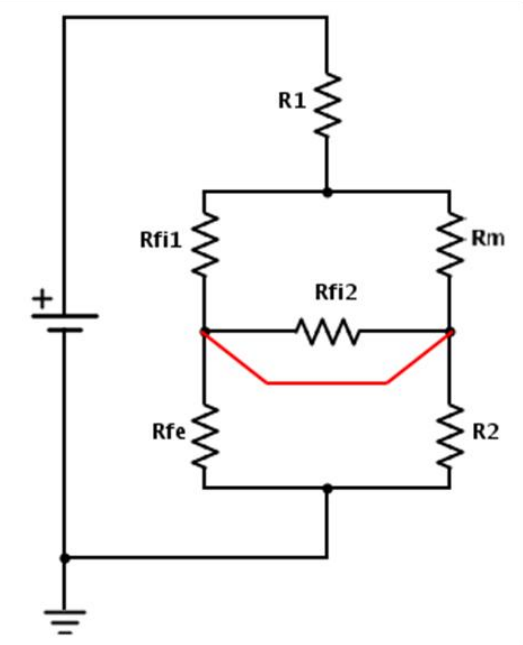

Figure 10. Electric circuit from a electric fuel pump with the pump housing grounded to the negative terminal. 


\section{Comparative test and results}

The figure 11 shows the final aspect of a fuel pump after $3000 \mathrm{~h}$ of durability test in E100 standard fuel comparing one sample without pump housing grounding and the other with pump housing grounded to the test bench ground terminal.

As verified on the figure 11(b) the final aspect of the grounded housing corresponds to the aspect found in parts from the field as shown on figure 3(b).

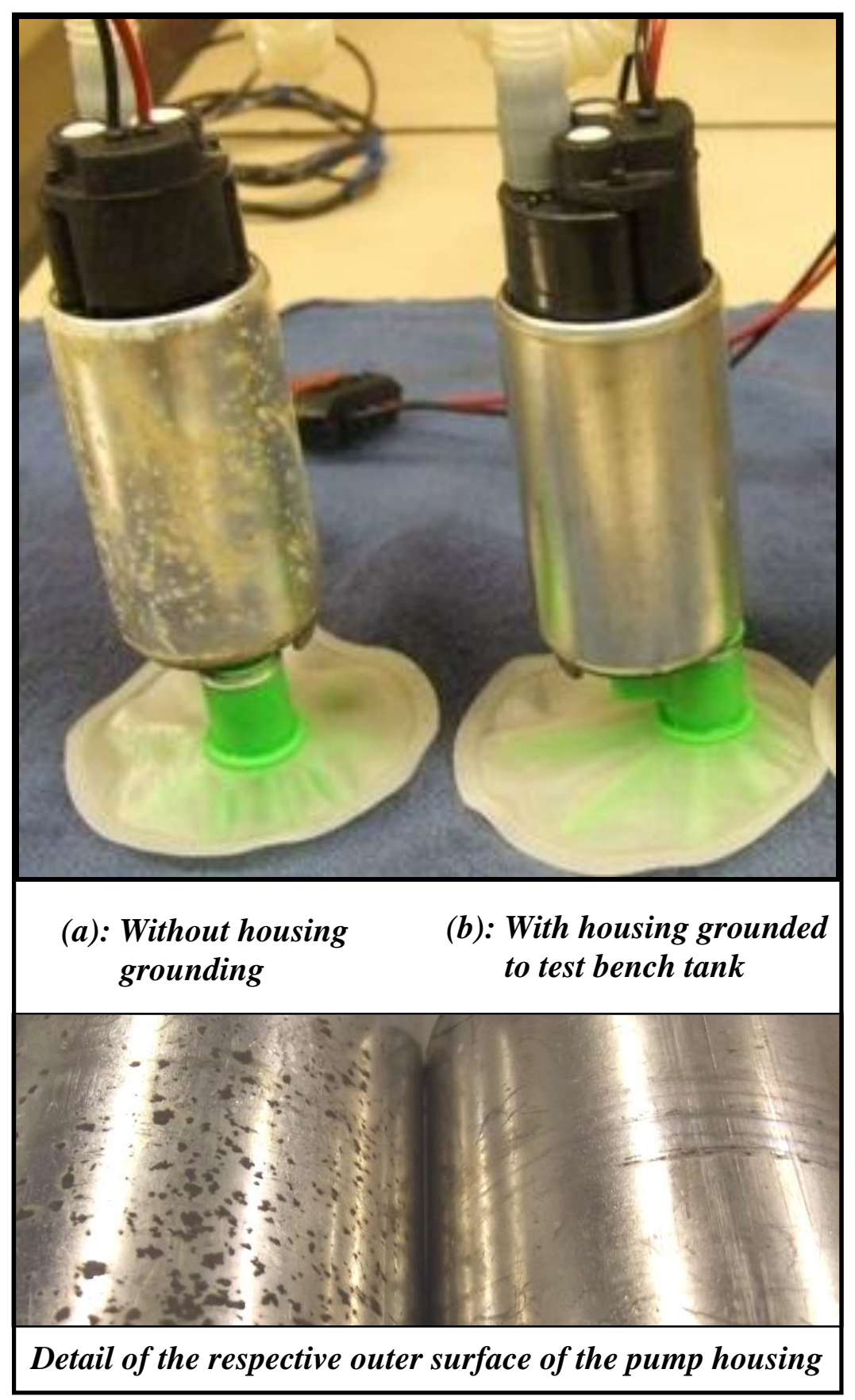

Figure 11. Aspect of outer surface of the electric fuel pump after 3000h durability in test bench in E100 


\section{CONCLUSIONS}

The recent position adopted by most of the automakers, regarding test fuel specifications for durability tests, leads to test conditions extremely aggressive for electric fuel pumps. The combination of different fuel formulas at high temperatures leads to high conductivities levels, creating a propitious condition for corrosion through electrolysis to happen.

However, it has been observed in samples after durability tests in test benches a corrosion on the outer surface of the pump housing that do not correspond to the behavior of parts from field. The reason for such corrosion is the electrical architecture of the test bench that creates an electric potential between the pump housing and the bench metallic tank, which in presence of the high conductivity fuel leads to an electrolysis process. This potential does not exist in vehicles with plastic fuel tanks or then has a reduced value in metallic fuel tanks, since they have a short distance between the electric fuel pump and the battery's negative terminal or are grounded at vehicle's frame.

In order to eliminate or minimize such pump housing corrosion, this study of the equivalent electric circuit of the system and subsequent tests showed that:

- By fuel pumps destined to vehicles with plastic fuel tank, grounding the pump housing of the sample under test to the ground terminal of the test bench tank interrupts the electrolysis process by balancing the potential of the components involved.

- By fuel pumps destined to vehicles with metallic fuel tank, connecting the pump negative terminal of the sample under test to the ground terminal of the test bench tank reduces the voltage difference potential between the pump housing and the test bench tank, leading to a lower corrosion potential

These test configurations can be considered closer to what is found in most of the vehicles, therefore they are recommended to be adopted as test procedure.

\section{References}

[1]. Pui Kei (P.K.) Yuen, John Beckett and William Villaire, "Automotive Materials Engineering Challenges and Solutions for the Use of Ethanol and Methanol Blended Fuels," SAE Technical Paper 2010-01-0729, 2010.

[2]. J. Galante-Fox, P. Von Bacho, C. Notaro and J. Zizelman, "E-85 Fuel Corrosivity: Effects on Port Fuel Injector Durability Performance -In," SAE Technical Paper 2007-01-4072, 2017.

[3]. Brazilian Government Standards; Technical Regulation ANP Nr. 3/2011 “Technical characteristics of Anhydrous and Hydrous Ethanol Fuel"

[4]. Brazilian Government Standards; Technical Regulation ANP Nr. 5/2001 "Technical characteristics of automotive Gasoline Type A and Type C"

[5]. ASTM Standard Specification, "D5798 - Standard Specification for Fuel Ethanol (Ed75Ed85) for Automotive Spark-Ignition Engines", 2009.

[6]. Working Committee of German automakers companies Audi, BMW, Daimler, Porsche, VW- Requirement Specifications AK-LH 15_2011-11 


\section{Abbreviations}

E0 : Brazilian gasoline Type A according to [4] without addition of ethanol.

E22 : Brazilian gasoline Type $\mathrm{C}$ according to [4] with addition of $22 \pm 4 \%$ of anhydrous ethanol.

E100: Brazilian 100\% Hydrous Ethanol Fuel according to [3]

E85 : Fuel blend, nominally 75 to 85 volume $\%$ of fuel ethanol and 25 to 15 additional volume \% of gasoline according to [5]

ANP : Agência Nacional do Petróleo (National Oil Agency). 